\title{
Hélène Diebold, Maurice Scève et la poésie de l'emblème
}

\section{Dario Cecchetti}

\section{(2) OpenEdition}

1 Journals

\section{Edizione digitale}

URL: https://journals.openedition.org/studifrancesi/4640

DOI: $10.4000 /$ studifrancesi.4640

ISSN: 2421-5856

\section{Editore}

Rosenberg \& Sellier

\section{Edizione cartacea}

Data di pubblicazione: 1 avril 2012

Paginazione: 133-134

ISSN: 0039-2944

\section{Notizia bibliografica digitale}

Dario Cecchetti, «Hélène Diebold, Maurice Scève et la poésie de l'emblème», Studi Francesi [Online], 166 (I | LVI) | 2012, online dal 30 novembre 2015, consultato il 19 novembre 2021. URL: http:// journals.openedition.org/studifrancesi/4640 ; DOI: https://doi.org/10.4000/studifrancesi.4640

Questo documento è stato generato automaticamente il 19 novembre 2021.

\section{(c) (i) (9)}

Studi Francesi è distribuita con Licenza Creative Commons Attribuzione - Non commerciale - Non opere derivate 4.0 Internazionale. 


\title{
Hélène Diebold, Maurice Scève et la poésie de l'emblème
}

\author{
Dario Cecchetti
}

\section{NOTIZIA}

HÉLÈNE DIEBOLD, Maurice Scève et la poésie de l'emblème, Paris, Classiques Garnier, 2011

(«Bibliothèque de la Renaissance», 5), pp. 491.

1 La thèse di H. Diebold si inserisce con prestigio - distinguendosi per una lodevole chiarezza-nel recente moltiplicarsi di studi su Scève e nel proliferare di ricerche sull'emblematica cinquecentesca. La prospettiva infatti della studiosa è quella dell'importanza fondamentale degli emblemi che accompagnano (in numero di cinquanta) i centoquarantanove dizains della raccolta: importanza tale per cui la Délie viene ricondotta a un preciso genere letterario, quello dei livres d'emblèmes. Assunto, questo, sostenuto fin dal 1948 da Verdun-Louis Saulnier ed ora condiviso dalla critica più recente, come testimoniano anche gli studi di Michael J. Giordano, di cui segnaliamo in questo numero della nostra rivista l'ultimo impegnativo lavoro. Nella Délie, secondo l'A., il confronto del sistema di segni rappresentato appunto dalla struttura 'emblematica' è particolarmente complesso, «poiché non si limita soltanto ai legami tra l'immagine e l'epigramma - che corrisponde qui al dizain-compagno - ma si estende all'insieme del testo. [...] Sul piano visivo, gli emblemi scandiscono il testo; il loro ritorno regolare, ogni nove dizains, modella la raccolta e partecipa alla sua messa in forma. [...] D'altronde le figure contribuiscono alla ricezione dell'opera: esse captano l'attenzione del lettore e la sua curiosità e lo conducono lungo un cammino che va dall'immagine al testo e dal testo all'immagine. Inoltre questi emblemi strutturano l'immaginario mediante ricorrenze lessicali e tematiche che essi cristallizzano nelle incisioni e nei 'motti'. Infine, e soprattutto, essi orientano la lettura in una direzione simbolica. Essi 'rappresentano' e 'significano', vale a dire impegnano in un processo di decifraggio e di disvelamento. [...] La dispositio del testo non dipende soltanto dalle circostanze della stampa, ma rivela un senso profondo e una concezione personale, 
innovativa e unica. [...] La Délie è un'opera costruita sulle tensioni e sui dissensi tra le figure emblematiche e i dizains» (pp. 16-17).

2 Nella prima parte del volume (Maurice Scève et l'emblème, pp. 25-125) l'A. ricostruisce il contesto lionese rinascimentale, per quanto concerne le problematiche editoriali e commerciali - in particolare quelle connesse alle tecniche di fabbricazione dei legni per le xilografie - e la storia del libro e dell'incisione nell'area di Lione. Inoltre confronta la composizione della Délie con quella di altre raccolte di emblemi della stessa epoca (1530-1560), mettendo in evidenza il carattere precursore dell'opera sceviana e giungendo a una definizione di un livre d'emblèmes che non può essere considerato tale tout court, ma si costituisce come un canzoniere in cui le incisioni, riprendendo la struttura dell'emblematica, formano delle unità complesse con i dizains che le seguono. La seconda parte ("Délie", fabrique d'images - Emblèmes et structures - Le microcosme délien, pp.129-282) affronta il problema della funzione degli emblemi e studia il loro concatenamento e la loro integrazione nel testo poetico, analizzando le corrispondenze lessicali e tematiche tra il testo degli emblemi e quello dei dizains, corrispondenze mediante le quali la Délie svela il suo microcosmo. Osservando queste corrispondenze è possibile, infatti, determinare le sequenze della Délie, costruite sul principio di reiterazione dei temi principali e la cui organizzazione mette in evidenza un'opera ciclica. Nella terza parte (L'itinéraire amoureux-La quête poétique, pp. 285-452) è questione dell'itinerario amoroso, così come esso è tracciato nella Délie: pertanto, la natura dell'amore sceviano viene definita in rapporto ai testi di Petrarca, di Marsilio Ficino, di Leone Ebreo. Per concludere, dal sostanzioso e interessante lavoro di $\mathrm{H}$. Diebold appare evidente - è la conclusione dell'A. - come «la struttura stessa della raccolta possa rinforzare la specificità della pratica emblematica di Scève e come la Délie non si presenti sotto l'aspetto di una galleria di emblemi, di una successione invariabile di unità autonome costituite dal motto/titolo, dall'immagine, da un epigramma e da un commento, bensì come la sua organizzazione si opponga al carattere amovibile dell'emblema e alla polivalenza delle incisioni, spesso riprese nella stessa opera da una prospettiva nondimeno diversa» (p. 454). 